Check for updates

London, UK

Cite this as: $B M J 2021 ; 374: n 2158$ http://dx.doi.org/10.1136/bmj.n2158 Published: 06 September 2021

\section{Why I ... volunteer as a Royal Parks ranger}

\section{Consultant anaesthetist Ramai Santhirapala talks to Kathy Oxtoby about how volunteering has helped her wellbeing during the pandemic}

Kathy Oxtoby

For years, Ramai Santhirapala has lived near Richmond Park in London, enjoying its beauty. But she found that the solace of nature was never more needed than during the pandemic when she faced the relentless pressure of working in an intensive care unit.

“During the pandemic I've been a patient facing worker and the intensity of its impact has been unfolding in front of my eyes. In the beginning I didn't know what the next day would bring. It was so important to take care of my health, so I made time to walk or jog in Richmond Park,” says Santhirapala.

Even though she was used to visiting the park, the pandemic made her appreciate its beauty even more. "I noticed how good I felt every time I went to the park," she says. "Being in a green space was so valuable, and the colours of nature are amazing."

The park renewed her energy during a stressful time and Santhirapala wanted to give something back in return. So she became a fully qualified Royal Parks volunteer ranger ${ }^{1}$ this March.

Now, for two hours twice a month she takes time out from her life as a consultant anaesthetist at Guy's and St Thomas' NHS Foundation Trust, London, and as a council member at the Royal College of Anaesthetists, to enhance and inform people's visits to the park.

A Sri Lankan born Tamil, Santhirapala moved to the UK when her parents migrated here during Sri Lanka's civil war. "As such I would describe myself as a blend of east and west, remaining close to my Sri Lankan roots, given the significant and close community here in London, while optimising the opportunities of living in London," she says.

Wanting to "give something back" is an inherent part of her culture, she feels.

"South Asian culture, not dissimilar to other cultures, is centred on kindness, gratitude, and looking for opportunities to help others alongside a strong work ethic. In that sense, it's hardly surprising that I became a doctor."

In her application to become a park ranger, Santhirapala was asked what she hoped to gain from and bring to the role. She said that her experiences as a doctor during the pandemic had "highlighted the importance of having green spaces for wellbeing," and that she would "enjoy learning about the park and educating others.”

During a month's induction process she learnt about the park, its common routes, and the responses to frequent questions from visitors. She also had awe inspiring experiences.

"During just one of my training sessions I watched two deer swim across a lake and helped make sure a swan, who had laid five eggs, was protected," she says. "I also heard a skylark singing and had a rare opportunity to see it swooping."

She enjoys informing visitors about the park, particularly when sharing her knowledge gives them a "lightbulb moment." "You know then that you've transformed their visit from a stroll in a park to really appreciating it in a whole different light-that moment is priceless."

Back at work, colleagues from her department and the college have been supportive when she shares stories of her new role. And her experience as an anaesthetist, which relies on effective communication in a compassionate and empathetic way, has been helpful, she says.

Santhirapala believes it's important for anyone involved in the NHS response to the pandemic to find avenues that rejuvenate and inspire them. Green spaces have inspired her to give back to the park, and she finds after two hours of ranging she is rejuvenated. "I volunteer my time. But I definitely get back more than I give," she says.

\section{How to make the change}

- No experience needed-simply an enthusiasm for the outdoors, an inquisitive mind, and good communication and team working skills

- Look up opportunities at national parks, councils, and environmental organisations who run similar volunteer opportunities. For example, if you are based in London, Royal Park volunteer opportunities can be found at www.royalparks.org.uk/get-involved/volunteer-with-us

- When in your volunteer role, set any day to day or work related concerns aside and be completely present

- Share your experiences with your family and friends-it's great to get feedback and may even encourage them to take up roles too

- Research has shown 120 minutes per week of nature has a positive impact on wellbeing ${ }^{2}$

The Royal Parks. Say hello to our volunteer rangers. www.royalparks.org.uk/get-involved/volunteer-with-us/volunteer-community-ranger

2 White MP, Alcock I, Grellier J, etal. Spending at least 120 minutes a week in nature is associated with good health and wellbeing. Sci Rep 2019;9:7730. doi: 10.1038/s41598-019-44097-3 pmid: 31197192 